\title{
Striatal DAT availability does not change after supraphysiological glucose loading dose in humans
}

\author{
Kyoungjune Pak ${ }^{1, *}$, Seongho Seo ${ }^{2, *}$, Myung Jun Lee ${ }^{3, *}$, Keunyoung Kim ${ }^{1}$, Sunghwan Suh ${ }^{4}$, Hyung-Jun Im ${ }^{5}$ and \\ In Joo Kim ${ }^{1}$
}

\author{
${ }^{1}$ Department of Nuclear Medicine and Biomedical Research Institute, Pusan National University Hospital, Busan, Republic of Korea \\ ${ }^{2}$ Department of Electronic Engineering, Pai Chai University, Daejeon, Republic of Korea \\ ${ }^{3}$ Department of Neurology, Pusan National University Hospital, Busan, Republic of Korea \\ ${ }^{4}$ Department of Internal Medicine, Dong-A University College of Medicine, Busan, Republic of Korea \\ ${ }^{5}$ Graduate School of Convergence Science and Technology, Seoul National University, Seoul, Republic of Korea
}

Correspondence should be addressed to K Pak: ilikechopin@me.com

*(K Pak, S Seo and M J Lee contributed equally to this work)

\begin{abstract}
Brain dopamine neurotransmission is regulated by the dopamine transporter (DAT), which drives reuptake of extracellular dopamine into the presynaptic neurons. We hypothesized that the glucose loading dose would affect the striatal DAT availability. An i.v. bolus injection of ${ }^{18} \mathrm{~F}$-FP-CIT was administered after infusion of low-dose glucose (300 mg/kg), high-dose glucose $(600 \mathrm{mg} / \mathrm{kg}$ ) or placebo (normal saline). The emission data were acquired over 90 min in 23 healthy male subjects. Substantial increases of binding potential $\left(\mathrm{BP}_{\mathrm{ND}} \mathrm{S}\right)$ from ventral striatum (VST), caudate nucleus, and putamen were observed after low-dose glucose loading $(+26.0,+87.0$, and $+37.8 \%)$ and after high-dose glucose loading $(+10.4,+51.9$, and $+22.0 \%)$. $\mathrm{BP}_{\mathrm{ND}} \mathrm{S}$ of the caudate nucleus and putamen showed significant differences ( $P=0.0472$ and 0.0221$)$ after placebo, low-dose glucose, and high-dose glucose loading. $\mathrm{BP}_{\mathrm{ND}} \mathrm{S}$ in the caudate nucleus and putamen after placebo, low-dose glucose, and high-dose glucose loading were positively intercorrelated with each other. In conclusion, striatal DAT changes after physiological glucose loading, but not after supraphysiological glucose loading in humans. DAT availabilities after placebo, low-dose glucose, high-dose glucose loading were correlated to each other in the caudate nucleus and putamen, but not in the VST. Therefore, sub-regional variability in DAT regulatory mechanisms mediated by insulin may exist in humans.
\end{abstract}

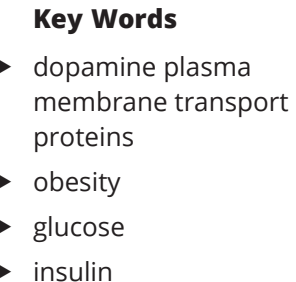

Endocrine Connections (2021) 10, 1266-1272

\section{Introduction}

The brain plays a critical role in controlling the energy balance of the body (1). Energy intake chronically exceeding energy expenditure leads to obesity $(2,3)$. Obesity is related with insulin resistance in muscle, liver as well as the brain $(4,5)$. As insulin is released from the pancreas in response to increased glucose levels as a consequence of food intake (6), it crosses the blood-brain barrier and stimulates insulin receptors (7).
There is growing evidence that insulin resistance is associated with neurodegenerative disorders such as Alzheimer's dementia (8) and Parkinson's disease $(9,10)$.

Food intake is controlled by a homeostatic system in the hypothalamus and by the hedonic reward system, both of which are closely linked (11). Dopamine is a neurotransmitter that plays a major role in the motivation and reward pathways (12). Feeding induces

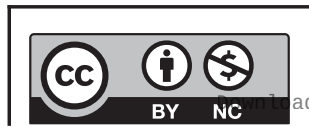

This work is licensed under a Creative Commons Attribution-NonCommercial 4.0 International License. ded from Bioscientifica.com at 04/26/2023 10:04:08AM 
dopamine release in the striatum, and dysfunction of the dopaminergic reward system can lead to overeating and obesity (13).

Brain dopamine neurotransmission is regulated by the dopamine transporter (DAT), which drives reuptake of extracellular dopamine into presynaptic neurons (14). In addition, DAT is a major target for various pharmacologically active drugs (14). However, previous studies showed no association between baseline DAT availability and BMI $(15,16,17)$. Recently, we reported the first human study that demonstrated substantial increases of striatal DAT after glucose loading and the association of DAT availability in the ventral striatum (VST) after lowdose glucose loading with BMI (18). We measured striatal DAT availability using dynamic PET scans with ${ }^{18} \mathrm{~F}$-FP-CIT, a radioligand with a high affinity for DAT, in response to glucose loading.

We hypothesized that the glucose loading dose might affect striatal DAT availability in humans. Therefore, we investigated DAT availability by exploring the following: (1) the association between the glucose loading dose and DAT availability and (2) the sub-regional variability of the effect of glucose loading on DAT availability in humans.

\section{Materials and methods}

\section{Subjects}

All participants signed an informed consent form prior to participation. Twenty-three healthy, non-obese male subjects were included in this study. Subjects who had more than 10\% change in weight over 6 months, were heavy smokers, or indicated a history of drug abuse, brain injury, neuropsychological disorders, or endocrine disorders were excluded. We screened the subjects at first about the medication and past neuropsychological history, and those without any known histories were included. On the day of each visit, the subjects were instructed to fast overnight for at least $12 \mathrm{~h}$ and abstain from smoking and alcohol consumption. Participants were not instructed to have any standardized meal prior to the experiment. The subjects visited the institution between 11:00 and 12:00 $\mathrm{h}$ to account for the diurnal variations in dopamine. The majority of the participants in this study were included in a previous study of striatal DAT changes after low-dose glucose loading (18). This study was approved by the institutional review board of Pusan National University Hospital (PNUH-1707-019-057).

\section{Study design}

Each subject visited the institution three times, on separate days, for three PET scans. Three PET scans were done within 2 months for each subject. During the visits, the height (m) and weight $(\mathrm{kg})$ of the subject were measured. BMI was calculated as follows: weight/height ${ }^{-2}$. Bilateral antecubital veins were cannulated: one for blood sampling and for injection of ${ }^{18} \mathrm{~F}$-FP-CIT and the other for low or high-dose glucose or placebo infusions. The subjects were blinded and randomly assigned for either low-dose glucose, highdose glucose, or placebo infusions. Over $10 \mathrm{~min}, 300 \mathrm{mg} / \mathrm{kg}$ (low-dose) or $600 \mathrm{mg} / \mathrm{kg}$ (high-dose) of glucose in a 50\% solution was administered. The placebo (normal saline) was also administered at the same speed and volume with $300 \mathrm{mg} / \mathrm{kg}$ of glucose (19). The serum glucose level (mg/dL) and insulin level $(\mu \mathrm{U} / \mathrm{mL})$ were measured before and after the infusions of glucose and placebo. Serum glucose level was determined through an enzymatic reference method using hexokinase with the Glucose HK Gen.3 (Roche Diagnostics $\mathrm{GmbH}$ ). Serum insulin level was determined through an electrochemiluminescence immunoassay method using Elecsys Insulin (Roche Diagnostics $\mathrm{GmbH}$ ). An i.v. bolus injection of ${ }^{18} \mathrm{~F}$-FP-CIT $(210.9 \pm 16.3 \mathrm{MBq})$ was administered after the infusion of glucose or placebo. The emission data were acquired over 90 min with 50 frames of progressively increasing durations $(15 \mathrm{~s} \times 8$ frames, $30 \mathrm{~s} \times 16$ frames, $60 \mathrm{~s} \times 10$ frames, $240 \mathrm{~s} \times 10$ frames, and $300 \mathrm{~s} \times 6$ frames) (20) using the Siemens Biograph 40 Truepoint PET/CT (Siemens Healthcare). The dynamic PET data were collected in the 3D mode, with 148 slices with image sizes of $256 \times 256$ and pixel sizes of $1.3364 \times 1.3364 \mathrm{~mm}^{2}$. These were reconstructed using an iterative method with a Gaussian filter. The study design is shown in Fig. 1.

\section{Image analysis}

For a volume-of-interest (VOI)-based analysis, an averaged image (0-10 min after injection) was created from dynamic PET frames and spatially normalized to ${ }^{15} \mathrm{O}$-Water PET template in statistical parametric mapping 5 (Wellcome Trust Centre for Neuroimaging, United Kingdom). To extract time-activity curves (TACs) of VOIs from full dynamic PET scans, Oxford-GSK-Imanova striatal atlas from FMRIB Software Library v5.0 (https://fsl.fmrib. ox.ac.uk/fsl) was applied, which is an atlas consisting of sub-striatal regions of ventral striatum (VST), caudate nucleus, and putamen segmented according to anatomical structure and manually delineated on the non-linear MNI

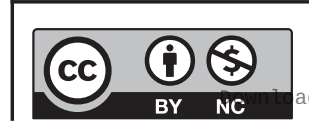

This work is licensed under a Creative Commons Attribution-NonCommercial 4.0 International License. ded from Bioscientifica.com at 04/26/2023 10:04:08AM 


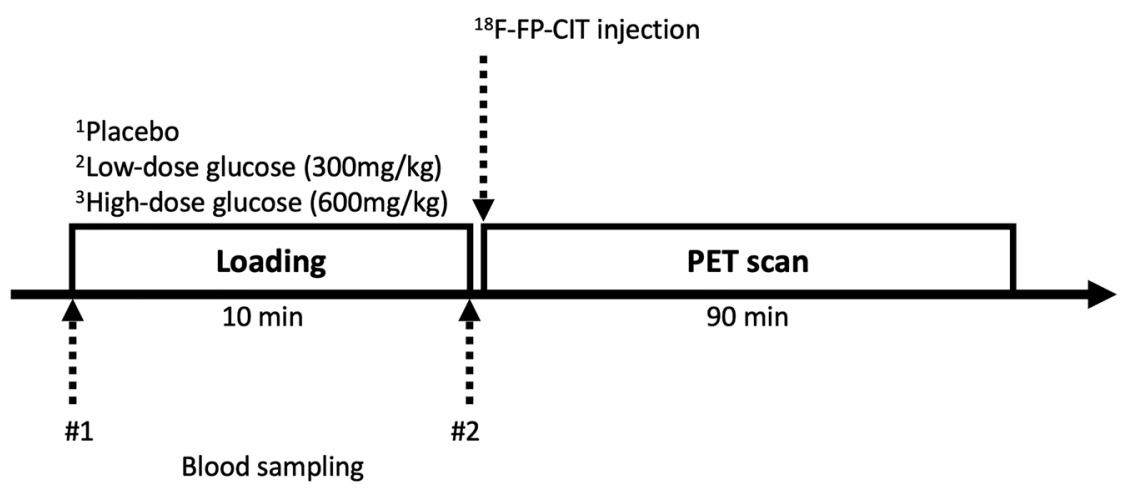

Figure 1

Study design.
152 template (21). DAT availability, expressed in terms of binding potential $\left(\mathrm{BP}_{\mathrm{ND}}\right)$, was measured by analysing TACs with the simplified reference tissue method (22) with the cerebellum as a reference. Image analysis was done using pmod version 3.6 (PMOD Technologies LLC, Zurich, Switzerland).

\section{Statistical analysis}

Normality was assessed using the D'Agostino \& Pearson normality test. Percentage changes of $\mathrm{BP}_{\mathrm{ND}}$ were calculated as follows: $\left(\mathrm{BP}_{\mathrm{ND}}\right.$ after glucose loading $-\mathrm{BP}_{\mathrm{ND}}$ after placebo loading $) / \mathrm{BP}_{\mathrm{ND}}$ after placebo loading $\times 100(\%)$. A repeatedmeasures ANOVA was used to compare the difference of $\mathrm{BP}_{\mathrm{ND}}$ between placebo, low-dose glucose, and high-dose glucose loading. A post hoc analysis was done using the Tukey test. The Pearson correlation analysis was used to determine the association between the $\mathrm{BMI}$ and $\mathrm{BP}_{\mathrm{ND}} \mathrm{S}$ from the VST, and between $\mathrm{BP}_{\mathrm{ND}} \mathrm{S}$ after placebo, low-dose glucose, and high-dose glucose loading. All analyses were conducted using Prism (v7.0d, GraphPad Software Inc).

\section{Results}

Twenty-three healthy males, with an age range of 20-30 years, and a mean age of $23.9 \pm 2.2$ years were included in this study. The mean BMI of the study group was $22.5 \pm 2.1 \mathrm{~kg} / \mathrm{m}^{2}$. The serum glucose and insulin levels were increased after low-dose $(P<0.0001,<0.0001)$, and high-dose $(P<0.0001,<0.0001)$ glucose loading. The mean increases of glucose and insulin levels were $21.4 \pm 12.8 \mathrm{mg} / \mathrm{dL}$ and $6.9 \pm 6.7 \mu \mathrm{U} / \mathrm{mL}$ after low-dose glucose loading and $303.3 \pm 34.6 \mathrm{mg} / \mathrm{dL}$ and $68.6 \pm 15.1$ $\mu \mathrm{U} / \mathrm{mL}$ after high-dose glucose loading, respectively. The subjects' characteristics are summarized in Table 1.

The average $\mathrm{BP}_{\mathrm{ND}}$ of the VST, caudate nucleus, and putamen were $4.65 \pm 1.48,3.06 \pm 2.03$, and $5.07 \pm 2.11$ with placebo loading, $5.01 \pm 1.83,4.07 \pm 1.82$, and $6.16 \pm 1.67$ with low-dose glucose loading, and $4.42 \pm 1.41,3.79 \pm 2.25$, and $5.59 \pm 2.07$ with high-dose glucose loading, respectively (Fig. 2). Low-dose glucose induced $\mathrm{BP}_{\mathrm{ND}}$ of the VST was negatively correlated with BMI $(\mathrm{r}=-0.4314 ; P=0.0398)$, however, neither placebo $(\mathrm{r}=-0.1892 ; P=0.3872)$ nor highdose glucose $(\mathrm{r}=-0.3144 ; P=0.1440)$ induced significant differences in $\mathrm{BP}_{\mathrm{ND}}$ of the VST.

Table 1 Characteristics of the subjects.

\begin{tabular}{|c|c|}
\hline Variables & \\
\hline Age (years) & $23.9 \pm 2.2$ \\
\hline Body mass index $\left(\mathrm{kg} / \mathrm{m}^{2}\right)$ & $22.5 \pm 2.1$ \\
\hline \multicolumn{2}{|l|}{ Glucose level (mg/dL) } \\
\hline \multicolumn{2}{|c|}{ Low-dose glucose loading } \\
\hline Before & $82.5 \pm 8.2$ \\
\hline After & $103.9 \pm 15.5$ \\
\hline \multicolumn{2}{|c|}{ High-dose glucose loading } \\
\hline Before & $80.8 \pm 7.9$ \\
\hline After & $384.1 \pm 36.0$ \\
\hline \multicolumn{2}{|l|}{ Insulin level ( $\mu \mathrm{U} / \mathrm{mL})$} \\
\hline \multicolumn{2}{|c|}{ Low-dose glucose loading } \\
\hline Before & $5.9 \pm 2.9$ \\
\hline After & $12.8 \pm 7.9$ \\
\hline \multicolumn{2}{|c|}{ High-dose glucose loading } \\
\hline Before & $6.4 \pm 3.5$ \\
\hline After & $75.1 \pm 38.0$ \\
\hline \multicolumn{2}{|l|}{$\mathrm{BP}_{\mathrm{ND}}$} \\
\hline \multicolumn{2}{|l|}{ Placebo loading } \\
\hline VST & $4.65 \pm 1.48$ \\
\hline Caudate nucleus & $3.06 \pm 2.03$ \\
\hline Putamen & $5.07 \pm 2.11$ \\
\hline \multicolumn{2}{|l|}{ Low-dose glucose loading } \\
\hline VST & $5.01 \pm 1.83$ \\
\hline Caudate nucleus & $4.07 \pm 1.82$ \\
\hline Putamen & $6.16 \pm 1.67$ \\
\hline \multicolumn{2}{|c|}{ High-dose glucose loading } \\
\hline VST & $4.42 \pm 1.41$ \\
\hline Caudate nucleus & $3.79 \pm 2.25$ \\
\hline Putamen & $5.59 \pm 2.07$ \\
\hline
\end{tabular}

Data are expressed as mean \pm S.D.

$\mathrm{BP}_{\mathrm{ND}}$, binding potential; VST, ventral striatum. 


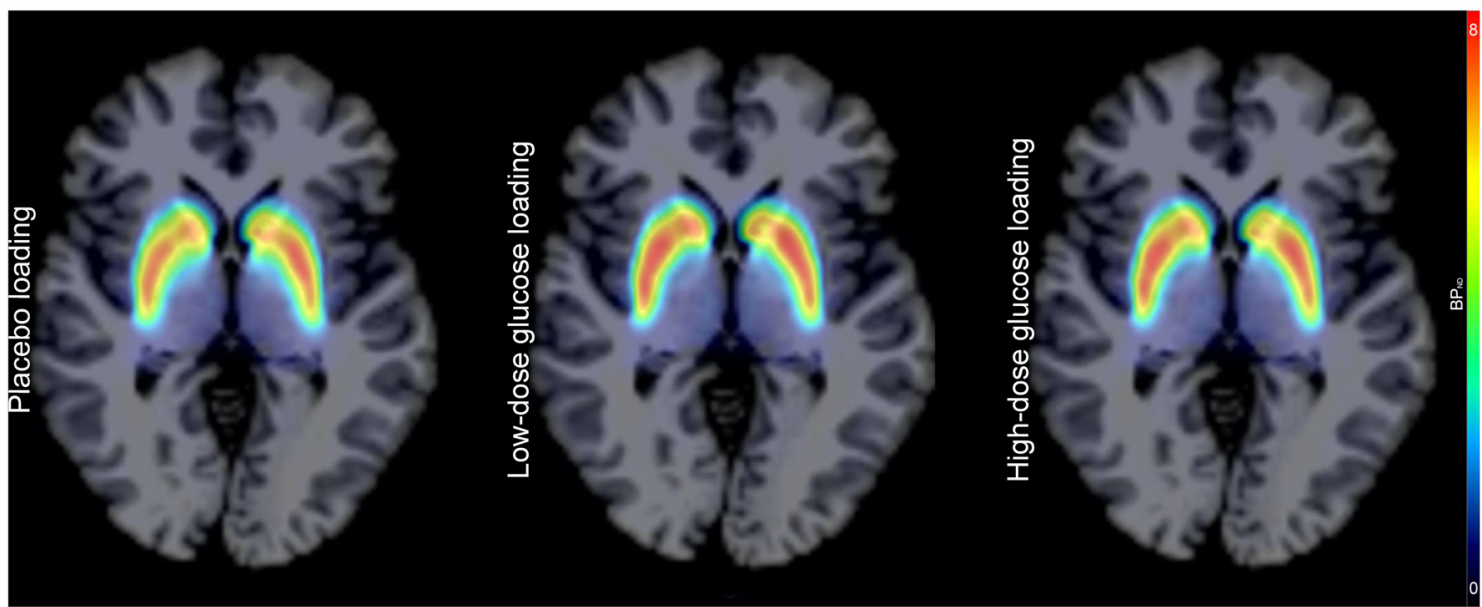

Figure 2

The average binding potential $\left(\mathrm{BP}_{\mathrm{ND}}\right)$ after placebo, low-dose glucose, and high-dose glucose loading.

Substantial increases of $\mathrm{BP}_{\mathrm{ND}} \mathrm{s}$ were observed in the VST, caudate nucleus, and putamen on average: $+26.0 \pm 91.9$, $+87.0 \pm 120.6$, and $+37.8 \pm 54.8 \%$ after low-dose glucose loading, and $+10.4 \pm 69.2,+51.9 \pm 104.0$, and $+22.0 \pm 56.5 \%$ after high-dose glucose loading, compared with those after placebo loading. Using a repeated-measures ANOVA, $\mathrm{BP}_{\mathrm{ND}} \mathrm{S}$ of the VST after placebo, low-dose, and high-dose glucose loading were not significantly different $(P=0.4324)$. However, $\mathrm{BP}_{\mathrm{ND}} \mathrm{S}$ of caudate nucleus $(P=0.0472)$, and putamen $(P=0.0221)$ showed a significant difference after placebo, low-dose, and high-dose glucose loading. In post hoc analysis, $\mathrm{BP}_{\mathrm{ND}} \mathrm{S}$ of putamen after low-dose glucose loading was higher than those after placebo loading (adjusted $P=0.0243$ ), however, there was no difference of $\mathrm{BP}_{\mathrm{ND}} \mathrm{S}$ of the putamen between placebo and high-dose glucose loading (adjusted $P=0.3896$ ), nor between low-dose and high-dose glucose loading (adjusted $P=0.2725$ ). Similarly, the $\mathrm{BP}_{\mathrm{ND}} \mathrm{S}$ of the caudate nucleus after low-dose glucose loading showed a trend towards higher levels than those after placebo loading (adjusted $P=0.0672$ ) (Fig. 3).

Correlation of $\mathrm{BP}_{\mathrm{ND}} \mathrm{S}$ from the VST, caudate nucleus, and putamen were analyzed to investigate how $\mathrm{BP}_{\mathrm{ND}} \mathrm{S}$ are associated with each other. In the VST, $\mathrm{BP}_{\mathrm{ND}} \mathrm{S}$ after placebo, low-dose glucose, and high-dose glucose loading were not significantly correlated with each other $(P>0.05)$. However, $\mathrm{BP}_{\mathrm{ND}} \mathrm{S}$ after placebo, low-dose glucose, and highdose glucose loading were positively correlated with each other in (1) the caudate nucleus: placebo vs low-dose glucose loading $(\mathrm{r}=0.4392 ; P=0.0360)$, low-dose glucose vs high-dose glucose loading $(\mathrm{r}=0.5854 ; P=0.0033)$, and placebo vs high-dose glucose loading $(\mathrm{r}=0.6043$; $P=0.0023)$ and (2) the putamen: placebo vs low-dose
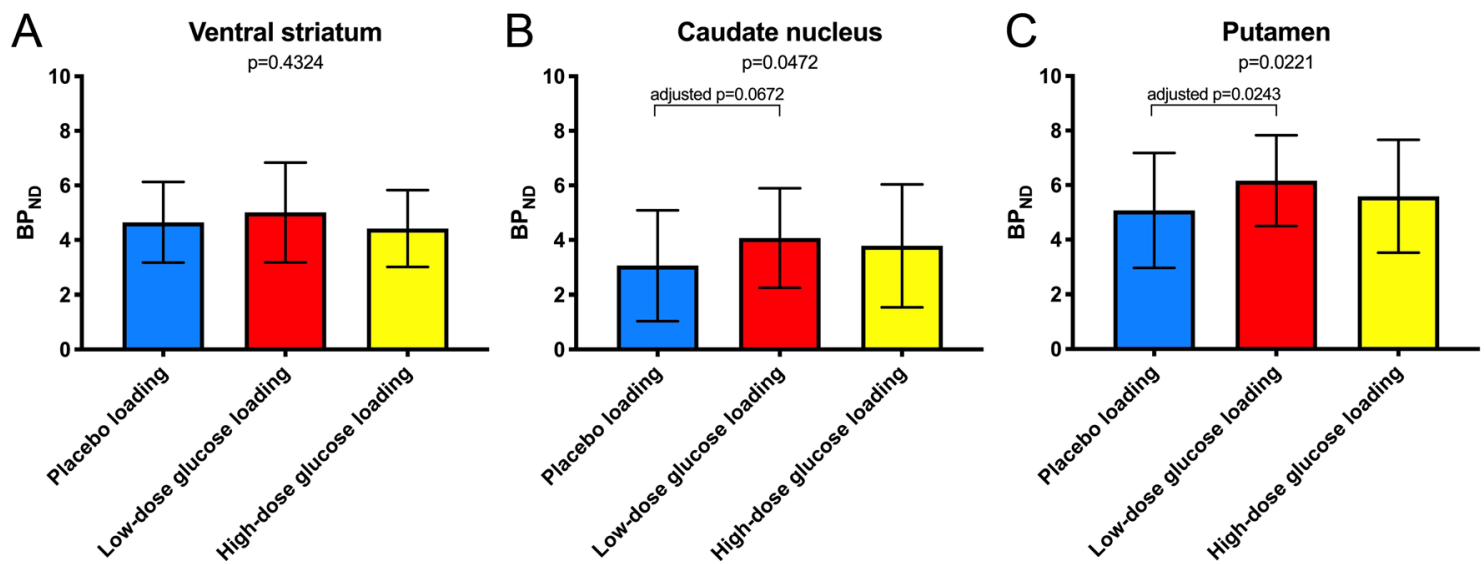

Figure 3

The repeated-measures ANOVA of binding potential $\left(\mathrm{BP}_{\mathrm{ND}}\right)$ after placebo, low-dose glucose, and high-dose glucose loading from $(\mathrm{A})$ ventral striatum, (B) caudate nucleus, and (C) putamen.

https://ec.bioscientifica.com https://doi.org/10.1530/EC-21-0355 (c) 2021 The authors Published by Bioscientifica Ltd

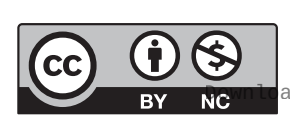

This work is licensed under a Creative Commons Attribution-NonCommercial 4.0 International License. ded from Bioscientifica.com at 04/26/2023 10:04:08AM 

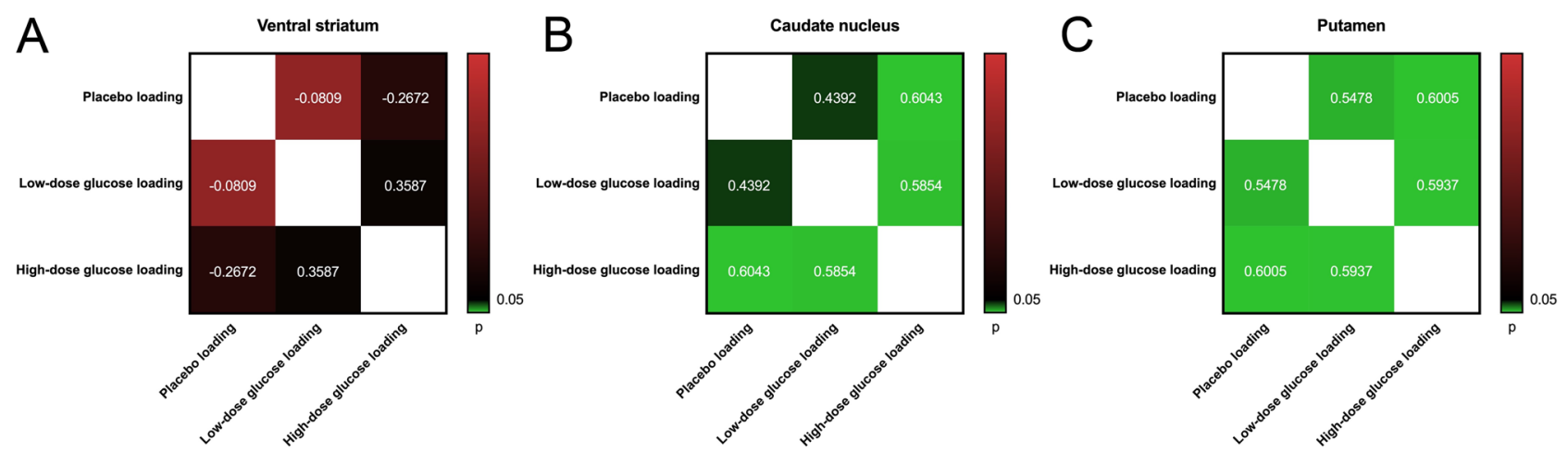

Figure 4

Correlations of $\mathrm{BP}_{\mathrm{ND}} \mathrm{S}$ after placebo, low-dose glucose, and high-dose glucose loading from (A) ventral striatum, (B) caudate nucleus, and (C) putamen.

glucose loading $(\mathrm{r}=0.5478 ; P=0.0068)$, low-dose glucose vs high-dose glucose loading $(\mathrm{r}=0.5937 ; P=0.0028)$, and placebo vs high-dose glucose loading $(\mathrm{r}=0.6005$; $P=0.0024$ ), respectively (Fig. 4).

\section{Discussion}

The results of the current study indicate the following. First, DAT availability in the dorsal striatum (caudate nucleus and putamen) after low-dose glucose loading were higher than those after placebo (baseline); however, those after high-dose glucose loading were not significantly different from those after placebo loading (baseline). Secondly, DAT availability in the VST did not show significant differences after low or high-dose glucose loading. Thirdly, DAT availability after placebo, low-dose glucose, and high-dose glucose loading in the dorsal striatum (caudate nucleus and putamen) were correlated with each other.

Insulin is released from the beta cells of the pancreas in response to increased glucose levels as a consequence of food intake (6). It rapidly crosses the blood-brain barrier and stimulates insulin receptors (7). In a study by Haltia et al., i.v. low-dose glucose loading did not produce a significant effect on dopamine receptor availability in healthy subjects (19). In animal studies, insulin activates the PI3K/Akt signalling pathway by acting on insulin receptors, which enhances surface expression of DAT (23). DAT actively promotes the reuptake of released dopamine, from the extracellular space into the presynaptic neuron $(14,24)$. Recently, substantial increases of striatal DAT availability after low-dose glucose loading and an association with DAT availability in the VST after low-dose glucose loading with BMI were reported by our group for the first time in humans (18). In this study, to investigate whether these changes of striatal DAT availability were associated with the glucose loading dose, striatal DAT availability was measured after both placebo (normal saline), $300 \mathrm{mg} / \mathrm{kg}$ (low-dose), and $600 \mathrm{mg} / \mathrm{kg}$ (high-dose) glucose loading in each subject. As healthy, non-obese male subjects without endocrine disorders were included in this study, the mean glucose level of $103.9 \mathrm{mg} / \mathrm{dL}$ after low-dose glucose loading could be considered as a physiological glucose loading level, and that of $384.1 \mathrm{mg} / \mathrm{dL}$ after high-dose glucose loading could be considered as supraphysiological glucose loading level. DAT availability was increased on average at least $26 \%$ after low-dose glucose loading similar with a previous study (18) and 10\% after highdose glucose loading. The repeated-measures ANOVA and post hoc analysis of DAT availabilities in the dorsal striatum (caudate nucleus and putamen) showed the significant difference after placebo, low-dose glucose, and high-dose glucose loading, particularly with higher levels after lowdose glucose loading. This is consistent with an animal study by Stouffer et al. in which DAT-mediated uptake was increased after exposure to a physiological concentration (30 nM) of insulin; however, it was unchanged from control after supraphysiological concentration (100 $\mathrm{nM}$ ) of insulin, which may be a consequence of insulin receptor desensitization or downregulation of signalling pathways at supraphysiological concentrations of insulin (25). However, the underlying mechanisms of blunted responses of DAT-mediated uptake in supraphysiological concentration of insulin remain unclear.

Different from DAT availability in the dorsal striatum (caudate nucleus and putamen), those in the VST were not significantly different after either low-dose or highdose glucose loading. DAT availability in the VST after placebo loading (baseline) did not show any significant correlation with BMI, consistent with previous studies $(15,16,17)$. However, DAT availability in the VST after lowdose glucose loading was negatively correlated with BMI. 
The VST plays a major role in processing reward cues and in the motivation to seek rewards (26). As DAT takes up the synaptic dopamine into presynaptic neurons, subjects with lower BMI may have a higher clearance of synaptic dopamine resulting in lower endogenous concentrations of dopamine in the VST, stopping food intake. However, this cannot discriminate if this association between DAT availability in the VST after low-dose glucose loading and BMI is a consequence or a cause of the eating behavior. Although the increase of DAT availability in the dorsal striatum may be modest, and not be important in clinical setting, these might be important to understand the mechanism of insulin action on brain dopaminergic system.

Although DAT availability in the dorsal striatum (caudate nucleus and putamen) after high-dose glucose loading was not different from those after placebo (baseline) or low-dose glucose loading, they were significantly correlated each other without an association with obesity, as measured by BMI, which was not seen in the VST. In addition, although the substantial increase of DAT availability after low-dose glucose loading was shown in both the VST and the dorsal striatum (caudate nucleus and putamen), the coefficient of variation of percentage changes of $\mathrm{BP}_{\mathrm{ND}}$ from the VST was $353.6 \%$, while those from the caudate nucleus and putamen were 138.7 and $145.0 \%$, respectively, which indicates that the response of DAT availability in the VST after low-dose glucose loading varies in each subject. In animal studies, subregional variation in DAT regulation within the striatum were reported in rats with chronic hyperinsulinemia (23). They also had reduced DAT-mediated uptake in the caudate/putamen with unchanged DAT-mediated uptake in the nucleus accumbens, which might be related to a compensatory decrease in the sensitivity of the insulin receptor (23). Therefore, region-dependent DAT regulatory mechanisms (ventral vs dorsal striatum) may exist in both animals and humans.

There are several limitations to this study. First, 23 healthy male subjects were included; as such, the sample size was small. Although the data was interpreted with cautions, sample size was not enough. As DAT availability and the response to glucose loading may be affected by sex, we enrolled only males in this study. Therefore, these findings may not be generalized in females, subjects with obesity, prediabetes, and diabetes. Secondly, as this is the first human study which investigated the association between the glucose loading dose and striatal DAT changes, non-obese subjects without endocrine disorders were included. From animal studies, streptozotocin induced insulin resistance is known to affect the action of DAT-mediated uptake and the release of dopamine (27). As there is growing evidence that insulin resistance is associated with neurodegenerative disorders, such as Alzheimer's dementia (8) and Parkinson's disease $(9,10)$, the relationship between insulin resistance and dopamine signalling in the human brain needs to be investigated further. Thirdly, $\mathrm{BP}_{\mathrm{ND}} \mathrm{s}$ that were measured did not distinguish between DAT density and affinity.

We have highlighted striatal DAT changes after a physiological glucose loading dose, not after a supraphysiological glucose loading dose. DAT availabilities after placebo, low-dose glucose, high-dose glucose loading were correlated each other in the dorsal striatum (caudate nucleus and putamen), but not in the ventral striatum. Sub-regional variability in DAT regulatory mechanisms mediated by insulin may exist in humans.

\section{Declaration of interest}

The authors declare that there is no conflict of interest that could be perceived as prejudicing the impartiality of the research reported.

\section{Funding}

This work was supported by Basic Science Research Program through the National Research Foundation of Korea (2020R1F1A1054201).

\section{Author contribution statement}

Kyoungjune Pak, Seongho Seo and Myung Jun Lee were involved in designing the study. Kyoungjune Pak, Hyung-Jun Im and In Joo Kim were involved in writing the manuscript. Keunyoung Kim and Sunghwan Suh were involved in image analysis.

\section{References}

1 Morton GJ, Meek TH \& Schwartz MW. Neurobiology of food intake in health and disease. Nature Reviews: Neuroscience 201415 367-378. (https://doi.org/10.1038/nrn3745)

2 Bellisle F, Drewnowski A, Anderson GH, Westerterp-Plantenga M \& Martin CK. Sweetness, satiation, and satiety. Journal of Nutrition 2012 142 1149S-1154S. (https://doi.org/10.3945/jn.111.149583)

3 Pak K, Kim SJ \& Kim IJ. Obesity and brain positron emission tomography. Nuclear Medicine and Molecular Imaging 201852 16-23. (https://doi.org/10.1007/s13139-017-0483-8)

4 Kahn BB \& Flier JS. Obesity and insulin resistance. Journal of Clinical Investigation 2000106 473-481. (https://doi.org/10.1172/JCI10842)

5 Heni M, Kullmann S, Preissl H, Fritsche A \& Haring HU. Impaired insulin action in the human brain: causes and metabolic consequences. Nature Reviews: Endocrinology 201511 701-711. (https:// doi.org/10.1038/nrendo.2015.173)

6 Schwartz MW, Woods SC, Porte Jr D, Seeley RJ \& Baskin DG. Central nervous system control of food intake. Nature $2000 \mathbf{4 0 4}$ 661-671. (https://doi.org/10.1038/35007534)

7 Woods SC, Schwartz MW, Baskin DG \& Seeley RJ. Food intake and the regulation of body weight. Annual Review of Psychology 200051 255-277. (https://doi.org/10.1146/annurev.psych.51.1.255) 
8 Diehl T, Mullins R \& Kapogiannis D. Insulin resistance in Alzheimer's disease. Translational Research 2017183 26-40. (https://doi. org/10.1016/j.trsl.2016.12.005)

9 Athauda D, Maclagan K, Skene SS, Bajwa-Joseph M, Letchford D, Chowdhury K, Hibbert S, Budnik N, Zampedri L, Dickson J, et al. Exenatide once weekly versus placebo in Parkinson's disease: a randomised, double-blind, placebo-controlled trial. Lancet 2017390 1664-1675. (https://doi.org/10.1016/S0140-6736(17)31585-4)

10 Poewe W \& Seppi K. Insulin signalling: new target for Parkinson's treatments? Lancet 2017390 1628-1630. (https://doi.org/10.1016/ S0140-6736(17)32101-3)

11 van Galen KA, Ter Horst KW, Booij J, la Fleur SE \& Serlie MJ. The role of central dopamine and serotonin in human obesity: lessons learned from molecular neuroimaging studies. Metabolism: Clinical and Experimental 201885 325-339. (https://doi.org/10.1016/j.metabol.2017.09.007)

12 Baik JH. Dopamine signaling in reward-related behaviors. Frontiers in Neural Circuits 20137 152. (https://doi.org/10.3389/ fncir.2013.00152)

13 Volkow ND, Wang GJ \& Baler RD. Reward, dopamine and the control of food intake: implications for obesity. Trends in Cognitive Sciences 201115 37-46. (https://doi.org/10.1016/j.tics.2010.11.001)

14 Vaughan RA \& Foster JD. Mechanisms of dopamine transporter regulation in normal and disease states. Trends in Pharmacological Sciences 201334 489-496. (https://doi.org/10.1016/j.tips.2013.07.005)

15 Thomsen G, Ziebell M, Jensen PS, da Cuhna-Bang S, Knudsen GM \& Pinborg LH. No correlation between body mass index and striatal dopamine transporter availability in healthy volunteers using SPECT and [123I]PE2I. Obesity 201321 1803-1806. (https://doi.org/10.1002/ oby.20225)

16 Nam SB, Kim K, Kim BS, Im HJ, Lee SH, Kim SJ, Kim IJ \& Pak K. The effect of obesity on the availabilities of dopamine and serotonin transporters. Scientific Reports 20188 4924. (https://doi.org/10.1038/ s41598-018-22814-8)

17 van de Giessen E, Hesse S, Caan MW, Zientek F, Dickson JC, Tossici-Bolt L, Sera T, Asenbaum S, Guignard R, Akdemir UO, et al. No association between striatal dopamine transporter binding and body mass index: a multi-center European study in healthy volunteers. Neuroimage 201364 61-67. (https://doi.org/10.1016/j. neuroimage.2012.09.011)

18 Pak K, Seo S, Kim K, Lee MJ, Shin MJ, Suh S, Im HJ, Park JJ, Kim SJ \& Kim IJ. Striatal dopamine transporter changes after glucose loading in humans. Diabetes, Obesity and Metabolism 202022 116-122. (https:// doi.org/10.1111/dom.13872)

19 Haltia LT, Rinne JO, Merisaari H, Maguire RP, Savontaus E, Helin S, Nagren K \& Kaasinen V. Effects of intravenous glucose on dopaminergic function in the human brain in vivo. Synapse $2007 \mathbf{6 1}$ 748-756. (https://doi.org/10.1002/syn.20418)

20 Lee JY, Seo SH, Kim YK, Yoo HB, Kim YE, Song IC, Lee JS \& Jeon BS. Extrastriatal dopaminergic changes in Parkinson's disease patients with impulse control disorders. Journal of Neurology, Neurosurgery, and Psychiatry 201485 23-30. (https://doi.org/10.1136/jnnp-2013-305549)

21 Tziortzi AC, Searle GE, Tzimopoulou S, Salinas C, Beaver JD, Jenkinson M, Laruelle M, Rabiner EA \& Gunn RN. Imaging dopamine receptors in humans with [11C]-(+)-PHNO: dissection of D3 signal and anatomy. Neuroimage $201154264-277$. (https://doi.org/10.1016/j. neuroimage.2010.06.044)

22 Lammertsma AA \& Hume SP. Simplified reference tissue model for PET receptor studies. Neuroimage 19964 153-158. (https://doi.org/10.1006/ nimg.1996.0066)

23 Jones KT, Woods C, Zhen J, Antonio T, Carr KD \& Reith ME. Effects of diet and insulin on dopamine transporter activity and expression in rat caudate-putamen, nucleus accumbens, and midbrain. Journal of Neurochemistry 2017140 728-740. (https://doi.org/10.1111/jnc.13930)

24 Mebel DM, Wong JC, Dong YJ \& Borgland SL. Insulin in the ventral tegmental area reduces hedonic feeding and suppresses dopamine concentration via increased reuptake. European Journal of Neuroscience 201236 2336-2346. (https://doi.org/10.1111/j.14609568.2012.08168.x)

25 Stouffer MA, Woods CA, Patel JC, Lee CR, Witkovsky P, Bao L, Machold RP, Jones KT, de Vaca SC, Reith ME, et al. Insulin enhances striatal dopamine release by activating cholinergic interneurons and thereby signals reward. Nature Communications 20156 8543. (https:// doi.org/10.1038/ncomms9543)

26 Caravaggio F, Raitsin S, Gerretsen P, Nakajima S, Wilson A \& GraffGuerrero A. Ventral striatum binding of a dopamine D2/3 receptor agonist but not antagonist predicts normal body mass index. Biological Psychiatry 201577 196-202. (https://doi.org/10.1016/j. biopsych.2013.02.017)

27 Owens WA, Williams JM, Saunders C, Avison MJ, Galli A \& Daws LC. Rescue of dopamine transporter function in hypoinsulinemic rats by a D2 receptor-ERK-dependent mechanism. Journal of Neuroscience 2012 32 2637-2647. (https://doi.org/10.1523/JNEUROSCI.3759-11.2012)

Received in final form 31 August 2021

Accepted 7 September 2021

Accepted Manuscript published online 7 September 2021 https://ec.bioscientifica.com https://doi.org/10.1530/EC-21-0355 (c) 2021 The authors Published by Bioscientifica Ltd
This work is licensed under a Creative Commons Attribution-NonCommercial 4.0 International License. ded from Bioscientifica.com at 04/26/2023 10:04:08AM 